\title{
Carbonization of Sulfuric-Acid-Impregnated Honeydew Rind for Metal Removal Application in Wastewater Treatment
}

\author{
${ }^{1}$ Z.M. Yunus, ${ }^{2} \mathrm{~N}$. Othman, ${ }^{3}$ R. Hamdan and ${ }^{1}$ N.N. Ruslan \\ ${ }^{1}$ Department of Science, Faculty of Science, Technology and Human Development, \\ ${ }^{2}$ Department of Water Engineering, Faculty of Civil and Environmental Engineering, \\ ${ }^{3}$ Deptarment of Civil Engineering, Faculity of Technology Engineering, \\ University Tun Hussein Onn Malaysia, Parit Raja, Malaysia
}

\begin{abstract}
In this study, honeydew rind a fruit waste was converted into activated carbon adsorbent as a potential metal removal from aqueous solution application. The waste was impregnated with sulfuric acid $\left(\mathrm{H}_{2} \mathrm{SO}_{4}\right) 10 \% \mathrm{v} / \mathrm{v}$ prior to carbonization. The effects of carbonization temperature of $470,490,510$ and $530^{\circ} \mathrm{C}$ on the development of pore surface were examined. The surface morphology and textural properties of produced ACs were characterized using surface analyzer and Field Emission Scanning Electron Microscope (FESEM). Percentage of yield $(79.23 \%)$ and ash content $(6.20 \%)$ were determined for each adsorbent produced adsorbent produced at optimal carbonization temperature of $510^{\circ} \mathrm{C}$. Surface textural analysis demonstrated comparable surface area of $429.16 \mathrm{~m}^{2} / \mathrm{g}$. FESEM micrograph showed the metal compound was infused into the pores after adsorption. This is evidently indicated by shiny and occupied pores compared to micrograph images before adsorption. This study has proven that honeydew rind, a non-value material can be transformed into an organic adsorbent with promising adsorbent characteristic and has a high potential to replace current commercial $\mathrm{AC}$ precursor.
\end{abstract}

$\underline{\text { Key words: Activated carbon, adsorption, honeydew rind, sulfuric acid, current commercial, surface textural }}$

\section{INTRODUCTION}

With the affect of rapid growth in idustrial sector felt worldwide, heavy metal pollution caused by the disposal of industrial effluent has become a significant issue of concerned. In this study, the researchers have discovered $\mathrm{Zn}(\mathrm{II})$ as an example of the heavy metal compound which contains a high concentration of effluent at (Gupta et al., 2015). The metal is a form of production residue that is commonly found in effluent concentration with other production wastes. Metal production and fabrication industries are among major contributors to the accumulation of dangerous pollutant (Roney and Osier, 2005). Permittable recommended daily dose of $\mathrm{Zn}$ (II) for men, women, children and infant is $15,12,10$ and $5 \mathrm{mg}$, respectively (Roney and Osier, 2005). The presence of heavy metals in the effluent is due to excess metal loads in the production.

The concentration of the pollutant life gradually accumulates in water sources. Consequently, this becomes a threat to nearby housing areas and aquatic area nearby and aquatic life. This sparks a health warning due to its harmful effects towards human internal organs as well as to aquatic life. In addition, the behavior of polluted water bodies is difficult to control. Its mobility eventually drives the public interest on the treated metals. Therefore, the need for proper, effiecient and cost effective method of heavy removal from indutrial waste water is critical to reduce the level of metal ions concentration in water bodies and eventually reduce the harmful health effects toward human beings and aquatic lives.

The most common wastewater treatment employed in heavy metal removal are membrane separation, ion exchange, bioremediation, chemical treatment and adsorption (Ajemba, 2013). Although, these techniques have been applied in wastewater remediation for decades, the processes have also created large volume of dangerous chemical waste. Besides that they are time-consuming and involve tedious technical operations. A number of researchers on this topic have come to a conclusion that there is still a lack of efficient methods for metal ion removal in wastewater (Gupta et al., 2016). Among the methods highlighted, it has been quoted that adsorption is the most practical and preferred technology in wastewater treatment due to its efficacy.

Corresponding Author: Z.M. Yunus, Department of Science, Faculty of Science, Technology and Human Development, Universiti Tun Hussein Onn Malaysia, Parit Raja, Malaysia 
Currently, adsorption technology employs AC where its precursor originated from costly natural materials such as coconut shells and coal. A high demand for the current precursor material and depletion of the source of materials has caused a tremendous rise in its market value. This circumstance has caused total adsorption operational to become less cost effective. Therefore, the challenge in running adsorption in removing metal ions is to use an alternative adsorbent due to cut its cost of operational costs. Thus, numerous studies have been conducted to find other alternative activated carbon precursor apart from coconut kernel (Sun et al., 2016; Abdullah and Sulaiman, 2013; Wankhade and Ganvir, 2013; Ahmed, 2016). Contemplating massive production of agricultural wastes from various agricultural industries initiated an investigation on new agricultural-waste-based activated carbon. The waste has been chosen in the production of activated carbon due to its abundance in availability. In addition, this characteristic can reduce cost of waste management indirectly. Agricultural waste possesses advantages in chemical property content as it is a form of lignocellulosic material which contains high carbon content, adsorptive functional groups. Hence, it is suitable for activated carbon production (Abdolali et al., 2014). Apart from that by converting the waste into an upgraded adsorbent the cost waste disposal could be reduced.

The present study has investigated the potential of Honey Dew Rind (HDR), a form of waste from a fruit juice industry to serve as an organic adsorbet for metal removal from aquoeus solution. The objectives of the study were to analyse its physicochemical properties and optimize the carbonization temperature in the production of its activated carbon. This is to fulfill its criteria as an adsorbent in metal removal application.

\section{MATERIALS AND METHODS}

Chemicals: Nitric acid 5\% v/v solution was prepared from nitric acid (QRec) $65 \%$. Various concentrations $\mathrm{H}_{2} \mathrm{SO}_{4}$ was prepared from sulfuric acid $95 \%(\mathrm{QRec})$. A stock solution of $\mathrm{Zn}(I)$ was prepared from $\mathrm{ZnSO}_{4} \cdot 7 \mathrm{H}_{2} \mathrm{O}$ (Sigma Aldrich). A series of desired concentration solutions was prepared by diluting the the stock solution. In order to control $\mathrm{pH}$ level of solutions a micro-pipette $(\mathrm{pH}$ meter, Thermo Fisher scientific-Singapore was used to manually add $1.0 \mathrm{M} \mathrm{NaOH}$ and $1.0 \mathrm{M} \mathrm{HCl}$ accordingly for $\mathrm{pH}$ adjustment. All chemicals used in this research were of analytical grade. In this research, all glassware and containers used in the experiments were immersed in $5 \% \mathrm{HNO}_{3}$ solution in order to ensure all glassware and containers were free from exsiting metals. The cleansing procedure was carried out to three days before these glassware were soaked in distilled water and oven-dried. Experimental research was repeated to three samples of each observation in order to obtain a triplicate data. Average values are reported based on the triplicate data (Othman and Asharuddin, 2013).

Raw materials: Honeydew rind was collected from restaurants, fruit shop and stalls located in Parit Raja, Batu Pahat, Malaysia. The fruit waste was immediately cleaned up to get rid of dirt and other visible forms of contaminant in the laboratory. The rind was then soaked in the nitric acid (5\%) for $6 \mathrm{~h}$ to remove existing metal content in the rind. Distilled water was used to rinse off any possible residue of acid by immersing the rind a container filled with distiled water. This step took place for about $24 \mathrm{~h}$ to minimize the remaining acid in the rind. Finally, the rind was oven-dried at $60^{\circ} \mathrm{C}$ for $8 \mathrm{~h}$ and kept in a dry storage. This sample will be used as precursor in honeydew rind activated carbon production.

\section{Experimental works}

Impregnation: Dried honeydew rind $\mathrm{HDR}$ was impregnated with sulfuric acid (10\%) $\mathrm{v} / \mathrm{v}$ for $6 \mathrm{~h}$. Then the chemical was drained off and the HDR was oven-dried at $110^{\circ} \mathrm{C}$.

Carbonization: Muffle furnace was used to carbonize the impregnated HDR. Firstly, the carbonization temperature was programmed at the rate of $5^{\circ} \mathrm{C} / \mathrm{min}$. It began at room temperature up till $300^{\circ} \mathrm{C}$. At this temperature, the heat was maintained for $15 \mathrm{~min}$ to allow water and organic compounds to evaporate from the sample. Secondly the temperature was raised to the final temperature, at the tested temperature of $470-530^{\circ} \mathrm{C}$. The sample was soaked at the final temperature for $30 \mathrm{~min}$ to complete the carbonization process. The carbonized HDR was cooled until it reached room temperature and kept in a tight glass container for further uses. Later in this study, carbonized HDR will be denoted as ACS in subsequent study in this study (Yunus et al., 2015).

Determination of yield and ash content: Determination of ACS yield was calculated by dividing the mass of sulfuric acid impregnated-HDR sample before carbonization with the mass of sample after the carbonization process. The calculation used Eq. 1 (Silgado et al., 2014). All the samples must be in dried form:

$$
\text { ACS yield percentage }=\frac{\mathrm{W}_{\mathrm{f}}}{\mathrm{W}_{\mathrm{i}}} \times 100 \%
$$

In this analysis approximately $1 \mathrm{~g}$ of dried sample was weighed in a dry and clean beaker. The sample was heated in a muffle furnace at $500^{\circ} \mathrm{C}$ until it was completely 
burned. This procedure took for $4 \mathrm{~h}$. After that it was allowed to cool down in a desiccator. The following Eq. 2 is used to find weight loss and ash content (Silgado et al., 2014):

$$
\begin{gathered}
\text { Percentage of ash in ACS }= \\
\frac{\text { Weight of sample after heating process } \times 100 \%}{\text { Weight of sample before heating process }}
\end{gathered}
$$

Where:

$\mathrm{W}_{\mathrm{i}}=$ The mass of the dried sample

$\mathrm{W}_{\mathrm{f}}=$ The final mass of sample when the sample has cooled down

Surface textural analysis: Surface analyzer was employed to determine pore characteristic of ACS. The specific surface area and pore distribution of the activated carbon was measured by nitrogen adsorption-desorption isotherm determination with a multiple-point gas adsorption measurement (SA 3100 Surface Analyser by Beckman Coulter)) at $77 \mathrm{~K}$. Brunauer, Emmet and Teller (BET) method was employed to determine the specific surface area at a relative pressure of 33.5 ATM. The micropore volume was calculated by using t-Plot micropore volume. Barrett-Joyner-Halenda $(\mathrm{BJH})$ model was used to determine the distribution of pore size. Prior to the measurement, approximately $0.05 \mathrm{~g}$ all the samples were crushed and powdered to shorten the time required for reaching equilibrium sample was put into sample tube holder followed by evacuation at $373 \mathrm{~K}$ for $1 \mathrm{~h}$ (Anisuzzaman et al., 2014).

Field Emission-Scanning Electron Microscopy (FESEM): A field scanning electron microscope (JEOL-JSM 7600F, USA) permits the observation and characterization of heterogeneous organic and inorganic on nanometer to micrometer (Cordero et al., 2013). Prior to the analysis, the samples were prepared by depositing the samples onto specimen stubs with conductive double sticky copper tapes. Then the sample was put inside the sputter for the purpose of coating the sample surface with $\mathrm{Au}-\mathrm{Pd}$ to avoid any electrical charging during examination (Yakout and Deen, 2011). Platinum sputtering of each sample was conducted for $120 \mathrm{sec}$ at $30 \mathrm{~mA}$ in a high vacuum until all the samples were completely covered before they were ready to be analyzed.

Metal adsorption: A known concentration of adsorbent was put in $250 \mathrm{~mL}$ conical flasks and allowed to have contact with $100 \mathrm{~mL}$ of aqueous solutions of required concentrations of $\mathrm{Zn}(\mathrm{II})$ at room temperature $\left(25 \pm 1^{\circ} \mathrm{C}\right)$. The solution was agitated using orbital shaker at $125 \mathrm{rpm}$ at a constant $\mathrm{pH}$. The mixtures were filtered to seperate the adsorbent and filtrate was collected and kept in glass sample bottles. The FESEM anaylsis was conducted to obtain micrograph of unloaded and loaded ACS to investigate any changes on the surface morphology of the adsorbent. This investigation is a pre-observation work which has been carried out in batch adsorption study for metal removal. However, the discussion of the whole study will be highlighted elsewhere (Yunus et al., 2015).

\section{RESULTS AND DISCUSSION}

Effects of carbonization temperature on the yield and ash content of activated carbon: Result of yield and ash analyses of ACS is presented in Table 1. The importance of yield and ash content information is related to the aspect of longevity and strength of an adsorbent. The carbon yield is defined as the weight of dried carbon to the weight of precursor. This yield strongly dependent on variables such as temperature and impregnation ratio (Ahmed, 2016). In this study, ACS has resulted higher percentage of yield at high carbonization.

A high carbonization temperature most likely affirms the data obtained from other researchers. The ash content however showed lower values but follows similar trend. The highest ash content was obtained by ACS4 which was carbonized at $530^{\circ} \mathrm{C}$. This analysis indicated that $510^{\circ} \mathrm{C}$ is a suitable carbonization temperature to produce high yield (79.23\%) and moderate ash content (6.20\%).

\section{Effect of carbonization temperature on the pore texture:} The surface textural investigation which includes specific surface area and porosity properties is important as they influence the characteristic of an adsorbent and its adsorption efficiency eventually. Table 2 shows the surface area, $\mathrm{S}_{\mathrm{BET}}$, micropores, mesopore and total volume of pores of ACS produced at particular carbonization temperature.

Table 1: Yield and ash content of ACS produced at different carbonization temperature

\begin{tabular}{lcc}
\hline Carbon & Yield (\%) & Ash content (\%) \\
\hline $\mathrm{ACS} 1$ & 21.92 & 4.36 \\
$\mathrm{ACS} 2$ & 46.94 & 4.12 \\
$\mathrm{ACS3}$ & $\mathbf{7 9 . 2 3}$ & 6.20 \\
$\mathrm{ACS} 4$ & 36.02 & 7.59 \\
\hline $\mathrm{ACS} 1=$ Carbonized at $470^{\circ} \mathrm{C}, \mathrm{ACS} 2=$ Carbonized at $490^{\circ} \mathrm{C}, \mathrm{ACS} 3=$ \\
Carbonized at $510^{\circ} \mathrm{C}, \mathrm{ACS} 4=$ Carbonized at $530^{\circ} \mathrm{C}$ &
\end{tabular}

Carbonized at $510^{\circ} \mathrm{C}, \operatorname{ACS} 4=$ Carbonized at $530^{\circ} \mathrm{C}$

Table 2: Textural properties of ACS

\begin{tabular}{lcccc}
\hline Carbon & $\mathrm{S}_{\mathrm{BET}}$ & $\mathrm{V}_{\text {micro }}(\mathrm{mL} / \mathrm{g})$ & $\mathrm{V}_{\text {meso }}(\mathrm{mL} / \mathrm{g})$ & $\mathrm{V}_{\text {total }}(\mathrm{mL} / \mathrm{g})$ \\
\hline ACS1 & 327.37 & 0.02 & 0.25 & 0.27 \\
ACS2 & 411.63 & 0.05 & 0.34 & 0.39 \\
ACS3 & $\mathbf{4 2 9 . 1 6}$ & $\mathbf{0 . 0 4}$ & $\mathbf{0 . 2 8}$ & $\mathbf{0 . 3 2}$ \\
ACS4 & 401.58 & 0.06 & 0.33 & 0.39 \\
\hline
\end{tabular}

ACS1 $=$ Carbonized at $470^{\circ} \mathrm{C}, \mathrm{ACS} 2=$ Carbonized at $490^{\circ} \mathrm{C}, \mathrm{ACS} 3=$ Carbonized at $510^{\circ} \mathrm{C}, \operatorname{ACS} 4=$ Carbonized at $530^{\circ} \mathrm{C}$ 


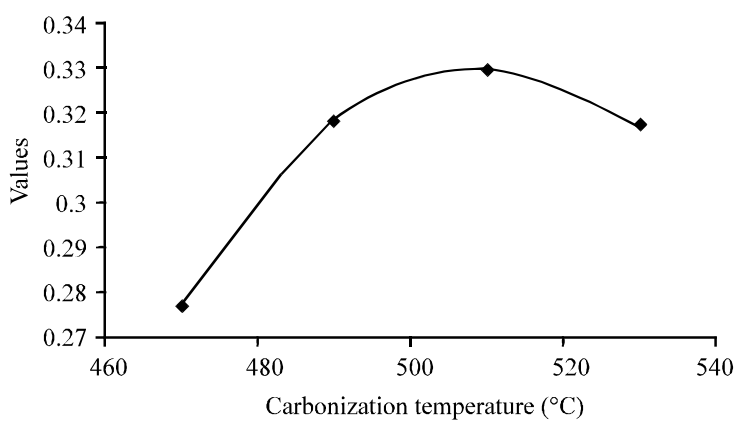

Fig. 1: The influence of total pore volume of ACS at different carbonization temperature

Pore evolution of ACS was obviously influenced by carbonization temperature. The carbon obtained at $470^{\circ} \mathrm{C}$, ACS1 exhibited the lowest $\mathrm{S}_{\mathrm{EET}}$, microporous and mesoporous. However, the values increased for the carbon produced at higher temperature $\left(490-530^{\circ} \mathrm{C}\right)$. Efficiency of an adsorbent is indicated by its surface area or active sites. The mesoporous and microporous volumes permit sufficient transportation of pollutants in aqueous condition. Thus, these characteristics are significantly important for wastewater treatment application. Based on the data, it is concluded that $10 \%$ $\mathrm{v} / \mathrm{v}$ sulfuric-acid-impregnated HDR prepared at carbonization temperature of $510^{\circ} \mathrm{C}$ is more suitable to produce well-developed surface morphology and porosity compared to other studied temperatures. Figure 1 illustrates the trend of pore distribution of ACS at each carbonization temperature. It changes significantly from $470-530^{\circ} \mathrm{C}$. This change consequently increased the formation of organic and volatile compound matters compared to the precursor. This investigation has clearly demonstrated that increasing carbonization temperature, pore development and new pore formation on the precusor's surface can be elevated. Apart from surface area, the information of pore development is undoubtedly essential in metal removal application due to its important role in both kinetic and equilibrium properties of porous material (Abbaszadeh et al., 2016). Thus, the study of structural heterogeniety of porous materials particularly used in adsorption could be the most critical aspect in adsorbent characterization.

Observation on surface morphology of acs before and after adsorption: Surface morphology pattern and surface characteristics of the adsorbent can be observed using FESEM. It is a major analytical observation employed in examining pertinent changes and development of porosity on the adsorbent surface. The FESEM micrograph of unloaded adsorbent surface is shown in Fig. 2a and Zn-loaded adsorbent surface is portrayed in Fig. 2b. The surface of unloaded pore was rough, uneven and
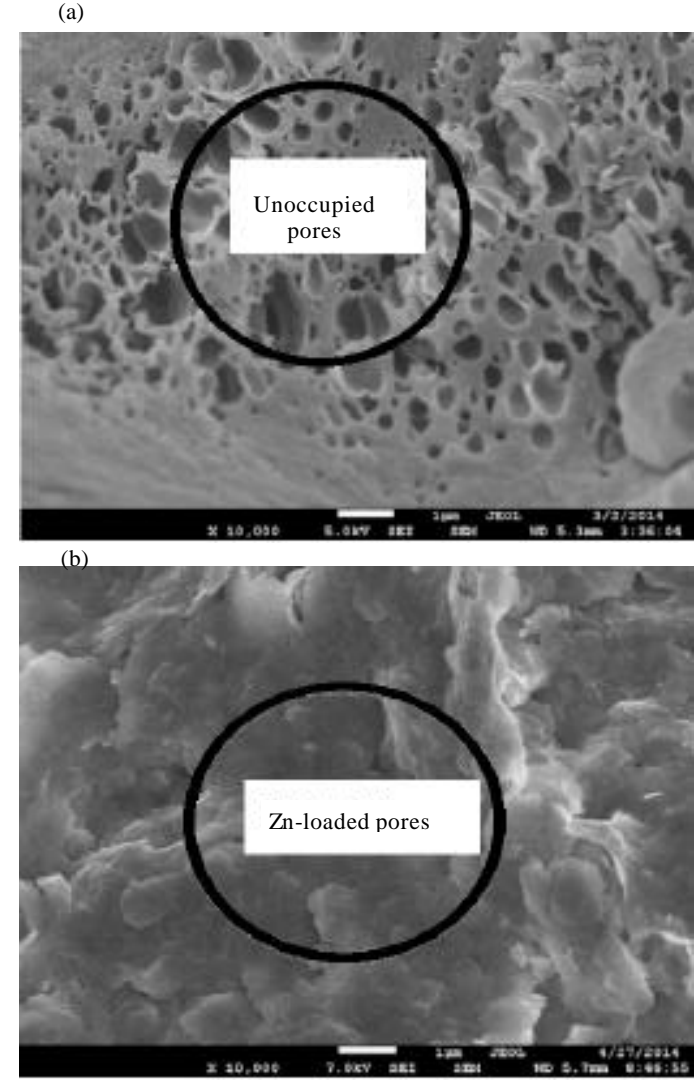

Fig. 2a): Surface morphology of ACS before metal adsorption and b) Surface morphology of ACS after metal adsorption

heterogeneous. The rough surface will increase the surface area's availability for metal adsorption. However, the adsorbent surface image as shown Fig. $2 b$ was observed shiny and loaded. The possible reason for this observation can be attributed to the bounded pores caused by the presence of zinc that has occupied the vacant pores. The reaction that occurred during adsorption process can be explained as precipitation or complexation of metal ions onto the adsorbent surface (Kaur et al., 2013).

\section{CONCLUSION}

Based on the result of this study, it has been proven that a non-expensive fruit waste; honeydew rind is a promising precursor material for the production of $\mathrm{AC}$ used in adsorption. A high percentage yield $79.23 \%$ and ash content $6.20 \%$ produced by ACS shows that honeydew rind can be categorized as a good quality adsorbent. The optimization of carbonization temperature played a crucial role in determining the most sufficient pore development and textural properties of honeydew 
rind activated carbon. The morphology studies indicated that the AC surface has clear pores with honeycomb-like structure. The FESEM micrograph showed that $\mathrm{Zn}$ has occupied most of the pores on the surface due to metal-surface interaction as a result of metal adsorption. This study has demonstrated that honeydew rind $\mathrm{AC}$ produced from $10 \%$ sulfuric acid impregnation process and carbonized at $510^{\circ} \mathrm{C}$ functions as a solid adsorbent with an optimal texture. Thus, there is a strong potential for honeydew rind to be one of the most promising options for the development of precursors for activated carbon production.

\section{REFERENCES}

Abbaszadeh, S., S.R.W. Alwi, C. Webb, N. Ghasemi and I.I. Muhamad, 2016. Treatment of lead-contaminated water using activated carbon adsorbent from locally available papaya peel biowaste. J. Cleaner Prod., 118: 210-222.

Abdolali, A., W.S. Guo, H.H. Ngo, S.S. Chen and N.C. Nguyen et al., 2014. Typical lignocellulosic wastes and by-products for biosorption process in water and wastewater treatment: A critical review. Bioresour. Technol., 160: 57-66.

Abdullah, N. and F. Sulaiman, 2013. The properties of the washed empty fruit bunches of oil palm. J. Phys. Sci., 24: $117-137$.

Ahmed, M.J., 2016. Preparation of activated carbons from date (Phoenix dactylifera L) palm stones and application for wastewater treatments: Review. Process Saf. Environ. Prot., 102: 168-182.

Ajemba, R.O., 2013. Adsorption of malachite green from aqueous solution using activated ntezi clay: Optimization, isotherm and kinetic studies. Intl. J. Eng. Trans. C. Aspects, 27: 839-854.

Anisuzzaman, S.M., C.G. Joseph, W.M.A.B.W. Daud, D. Krishnaiah and H.S. Lee, 2014. Preparation and characterization of activated carbon from Typha orientalis leaves. Int. J. Ind. Chem., 6: 9-21.

Cordero, H.T., L.G.J. Aguilar, D.I.M. Castillo, V.H. Montoya and A.B. Petriciolet et al., 2013. Synthesis and adsorption properties of activated carbons from biomass of prunus domestica and jacaranda mimosifolia for the removal of heavy metals and dyes from water. Ind. Crops Prod., 42: 315-323.
Gupta, V.K., A. Nayak, B. Bhushan and S. Agarwal, 2015. A critical analysis on the efficiency of activated carbons from low-cost precursors for heavy metals remediation. Crit. Rev. Environ. Sci. Technol., 45: 613-668.

Gupta, V.K., P.J.M. Carrott, R. Singh, M. Chaudhary and S. Kushwaha, 2016. Cellulose: A review as natural, modified and activated carbon adsorbent. Bioresour. Technol., 216: 1066-1076.

Kaur, R., J. Singh, R. Khare, S.S. Cameotra and A. Ali, 2013. Batch sorption dynamics, kinetics and equilibrium studies of $\mathrm{Cr}$ (VI), $\mathrm{Ni}$ (II) and Cu (II) from aqueous phase using agricultural residues. Appl. Water Sci., 3: 207-218.

Othman, N. and S.M. Asharuddin, 2013. Cucumis Melo Rind as Biosorbent to Remove Fe (II) and Mn (II) from Synthetic Groundwater Solution. In: Advanced Materials Research, Ruhiyuddin, M.Z., C.P. Faizul and D. Murizam (Eds.). Trans Tech Publications, Switzerland, pp: 266-271.

Roney, M. and M. Osier, 2005. Toxicological profile for zinc. US. Department Health Serv. ASTDR., 2005: $87-118$.

Silgado, K.J., G.D. Marrugo and J. Puello, 2014. Adsorption of chromium (VI) by activated carbon produced from oil palm endocarp. Chem. Eng. Trans., 37: 721-726.

Sun, Y., H. Li, G. Li, B. Gao and Q. Yue et al., 2016. Characterization and ciprofloxacin adsorption properties of activated carbons prepared from biomass wastes by $\mathrm{H} 3$ PO 4 activation. Bioresour. Technol., 217: 239-244.

Wankhade, A.A. and V.N. Ganvir, 2013. Preparation of low cost activated carbon from tea waste using sulphuric acid as activating agent. Intl. Res. J. Environ. Sci., 2: 53-55.

Yakout, S.M. and G.S.E. Deen, 2011. Characterization of activated carbon prepared by phosphoric acid activation of olive stones. Arabian J. Chem., 9: 1155-1162.

Yunus, Z.M., N. Othman, R. Hamdan, N.N. Ruslan and N.A. Kasin, 2015. Activated carbon from honeydew rind as adsorbent for zinc removal in aqueous solutions. Appl. Mech. Mater., 774: 1246-1250. 